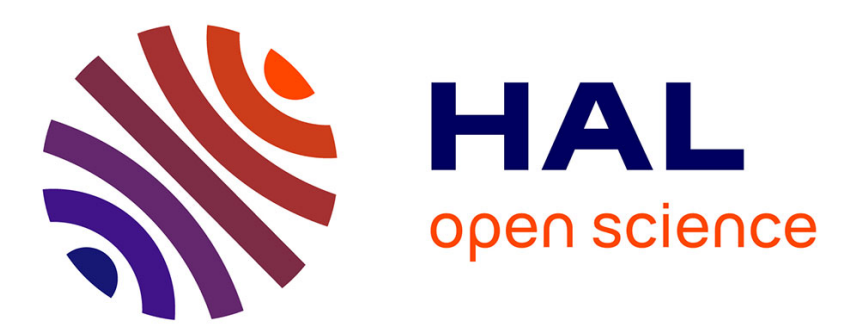

\title{
Influence of Concrete Carbonation on Electromagnetic Permittivity Measured by GPR and Capacitive Techniques
}

Xavier Derobert, Géraldine Villain, Jean-Paul Balayssac

\section{- To cite this version:}

Xavier Derobert, Géraldine Villain, Jean-Paul Balayssac. Influence of Concrete Carbonation on Electromagnetic Permittivity Measured by GPR and Capacitive Techniques. Journal of Environmental and Engineering Geophysics, 2018, 23 (4), pp.443-456. 10.2113/JEEG23.4.443 . hal-03255703

\section{HAL Id: hal-03255703 \\ https://hal.science/hal-03255703}

Submitted on 9 Jun 2021

HAL is a multi-disciplinary open access archive for the deposit and dissemination of scientific research documents, whether they are published or not. The documents may come from teaching and research institutions in France or abroad, or from public or private research centers.
L'archive ouverte pluridisciplinaire HAL, est destinée au dépôt et à la diffusion de documents scientifiques de niveau recherche, publiés ou non, émanant des établissements d'enseignement et de recherche français ou étrangers, des laboratoires publics ou privés. 


\section{INFLUENCE OF CONCRETE CARBONATION ON ELECTROMAGNETIC PERMITTIVITY MEASURED BY GPR AND CAPACITIVE TECHNIQUES}

10 This paper addresses the effect of concrete carbonation on the propagation and dispersion of electromagnetic (EM) waves and the capability of two electromagnetic non-destructive techniques to detect this pathology. A capacitive technique operating at low frequency (around $33 \mathrm{MHz}$ ) and a ground penetrating radar (GPR called the 1.5-GHz antenna) are tested for the monitoring of reinforced concrete structures. To better understand the phenomena involved in concrete carbonation, the results of two complementary experimental campaigns are analyzed for saturated concretes. First, the dispersion curves of complex permittivity are measured for both carbonated and non-carbonated samples by a cylindrical coaxial EM cell. Due to carbonation, the permittivity decreases and the level of dispersion reduces slightly. Second, using GPR (coupled at approx. $900 \mathrm{MHz}$ ) and capacitive measurements conducted on controlled slabs, it is confirmed that the real part of the relative permittivity decreases within a range of 2 at $33 \mathrm{MHz}$ and a range of 1 toward $900 \mathrm{MHz}$, while the radar signal amplitude increases.

The diagnosis of concrete structures has become a major issue over time. Among the main durability indicators, salt ingress and carbonation constitute the major causes in most deterioration processes, facilitated by water content as a common agent, thus leading to rebar corrosion. Electromagnetic (EM) non-destructive testing (NDT) techniques have, through numerous studies, revealed their sensitivity and efficiency in evaluating such durability indicators. These studies have mainly been devoted to water content evaluation or chloride ingress monitoring in concrete [Robert, 1998; Soustos et al., 2001; Laurens et al., 2002; Peer et al., 2003; Hugenschmidt and Loser, 2008; Dérobert et al., 2008; Kalogeropoulos et al., 2013; Villain et al., 2015; Hong et al., 2017; Dérobert and Villain, 2017a], but little emphasis has been paid to carbonation [Hong et al., 2017; Balayssac et al., 2012; Dérobert and Villain, 2017b].

Carbonation is a major contributor to concrete degradation. Due to climate change, carbon dioxide $\left(\mathrm{CO}_{2}\right)$ content has been drastically increasing in the atmosphere, reaching above $400 \mathrm{ppm}$ in the world and in 2016 extending to the less polluted parts of the Indian Ocean [Ballantyne et al., 2012; Ramonet et al., 2016]. In urban areas, the mean value is even higher. Moreover, due to human activity, daily variations are

Preprint 
considerably higher in suburban areas than in rural zones; for example, in suburban London and coastal Ireland, variation factors of 72 can be found [Hernández-Paniagua et al., 2015]. Concrete structures are therefore slightly more affected by carbonation [De Larrard et al., 2014]. The acidification in cover concrete leads to severely corrosive pathologies of reinforced concrete structures [Tuutti, 1982; Parrott, 1987; Dunster, 1989; Papadakis et al., 1991a-b; Villain and Platret, 2006; Villain and Thiéry, 2005].

In light of this context and given that the wave propagation of EM NDT techniques is sensitive to both porosity and chemical changes in concrete material, such techniques can become useful tools in estimating the carbonation level of cover concrete. The aim of this paper is to study the effect of carbonation on the propagation and dispersion of EM waves at low and higher radar frequencies in order to make use of the capacitive technique and GPR during inspections of reinforced concrete structures. A previous study [Dérobert and Villain, 2017b] found a negligible effect of carbonation on dry concrete mix, hence the present paper is focused on saturated mixes.

After an overview of the concrete carbonation process and its consequences provided in the next section, the experimental programs of two complementary research projects [Balayssac et al., 2012; Dérobert and Villain, 2017b] are presented, including their concrete mixes, conditioning and the EM NDT techniques employed. The final section is devoted to reporting results and discussing their analysis.

(1)

\section{The concrete carbonation process}

One of the main causes of corrosion in reinforced concrete structures is carbonation, a phenomenon due to the penetration of carbon dioxide into cover concrete [Tuutti, 1982; Parrott, 1987]. The carbonation process leads to physicochemical changes in the cover concrete, which can be detailed as follows.

\section{$\underline{2.1 \text { Carbonation process }}$}

The reinforcing bars in reinforced concrete structures are physically and chemically protected from corrosion by the concrete. From a chemical point of view, the very high $\mathrm{pH}$-value of concrete (around 12.6) leads to a passivation of the reinforcement. Over time, atmospheric carbon dioxide $\left(\mathrm{CO}_{2}\right)$ can penetrate into concrete, dissolve in the pore solution and react with portlandite $\left(\mathrm{Ca}(\mathrm{OH})_{2}\right)$, as illustrated by Equation (1) or with C-S-H according to Equation (2):

$$
\mathrm{Ca}(\mathrm{OH})_{2}+\mathrm{CO}_{2} \rightarrow \mathrm{CaCO}_{3}+\mathrm{H}_{2} \mathrm{O}
$$

$$
\text { C-S-H }+\mathrm{CO}_{2} \rightarrow \mathrm{CaCO}_{3}+\mathrm{H}_{2} \mathrm{O}+\text { silica gels }
$$

These effects result in water formation, the precipitation of calcium carbonates $\left(\mathrm{CaCO}_{3}\right)$ and amorphous silica gels [Dunster, 1989]. The equilibrium between portlandite, C-S-H and the hydroxide ions of the pore solution is thus changed, leading to the gradual consumption of all reserve basicity and then to a drop in $\mathrm{pH}-$ value from about 13 to 9 . The reinforcement is no longer chemically protected and more likely to corrode.

According to numerous studies [Tuutti, 1982; Parrott, 1987; Dunster, 1989; Papadakis et al., 1991a-b; Villain and Thiéry, 2005; Villain and Platret, 2006], carbonated depth increases with the square root of time 
following a simplified Fick's diffusion law. The parameters of this law depend on many factors, including concrete mix design, especially the water-cement ratio, and fabrication and environmental exposure conditions. Among existing carbonation models, Papadakis et al. [1991a-b] were able to determine the depth of carbonation and induced mass changes in the various mix components; their work encompassed the cement chemical analysis and external conditions detailed in Section 3.

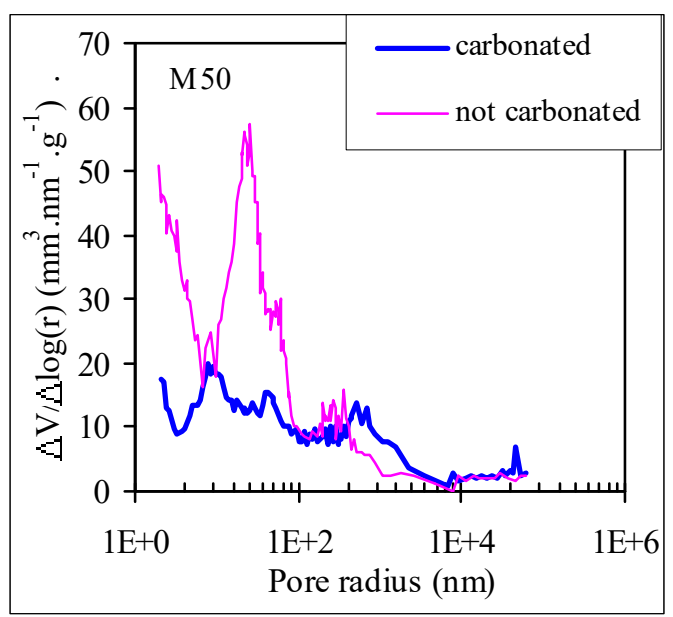

Fig. 1: Example of pore size distribution in both carbonated and non-carbonated concrete [Villain and Platret, 2006].

\subsection{Consequences on physical properties}

The carbonation of concrete induces several consequences. The first is a reduction in porosity due to $\mathrm{CaCO}_{3}$ precipitation and the formation of amorphous silica gels filling the small pores [Parrott, 1987; Dunster, 1989; Villain and Thiéry, 2005; Glass et al., 1991], as shown in Figure 1. The order of magnitude of this porosity reduction lies between $2 \%$ and $4 \%$ for two concretes mixed with Portland cement (namely M25 and M50), with a mean compressive strength of $25 \mathrm{MPa}$ and $50 \mathrm{MPa}$ at 28 days, according to Villain and Thiéry [2005].

The other major consequences are: the release of liquid water that can locally change the water content (hence the preference for conducting comparative measurements under saturated conditions); the $\mathrm{pH}$-value decrease from roughly 13 to 9 ; and carbonation-induced change in the ionic content of the pore solution.

Three indirect and secondary consequences can be cited. First, let's observe the increase in mechanical strength [Parrott, 1987]. Second, carbonation induces a change in both permeability and the diffusion coefficient. These transport coefficients often decrease following a drop in porosity; conversely, an increase can be noted for very porous concretes, witnessed as a larger pore appearance and a tortuosity reduction [Villain and Thiéry, 2005]. Third and last, the resistivity of concrete, which increases with carbonation, is attributed to a loss of porosity and the disappearance of mobile ions $\left(\mathrm{OH}^{-}\right)$from the pore solution [Alonso et al., 1988; Glass et al., 1991]. The ratio of resistivities measured on saturated carbonated (C) and noncarbonated $(N C)$ specimens equals between 1.8 and 8 for M25 to M50 concretes mixed with Portland cement [Villain and Thiéry, 2005].

\footnotetext{
Various experimental methods can be performed to evaluate concrete carbonation. The best known and
} 
easiest to use is a $\mathrm{pH}$-indicator, like phenolphthalein, sprayed onto a freshly broken surface sample. This method allows defining a depth of carbonation $\mathrm{P}_{\mathrm{c}}$ correlated with the pore solution $\mathrm{pH}$-value [AFPCAFREM, 1997]. Another method, based on $\mathrm{CO}_{2}$ fixation, entails tracking the mass increase by weighing. The weakness of this method lies in the fact that weight can be biased by moisture change, e.g. concomitant drying due to accelerated carbonation taking place in a chamber with relative humidity $(\mathrm{RH})$ controlled at around $50 \%$. For both non- and fully-carbonated specimens, the bulk porosity reduction can be measured by water saturation under vacuum [AFPC-AFREM, 1997].

\section{Experimental campaigns}

109 The results presented herein stem from two complementary research programs sponsored respectively by the French Ministry of Ecology (MTES) and EDF company (electric utility), and the French National Research Agency (ANR). The first program, called Epsilon, seeks to quantify, through several large experimental designs [Dérobert and Villain, 2017a-b], the influence of composition parameters and concrete conditions on permittivity within a frequency band of approx. [50 MHz - $1 \mathrm{GHz}$ ]. The second program, ANR-SENSO, was devoted to evaluating durability indicators (namely porosity and carbonation depth) by applying various types of NDT methods [Balayssac et al., 2012] on several controlled homogeneous mixes in the laboratory. Since the aggregate and cement contents were identical, these common components offer the possibility of collating results for the two projects.

\subsection{Concrete mix design from the Epsilon project}

120 The mix design used for the Epsilon experimental program is presented in Table 1, which lists 12 concretes 121 submitted to carbonation. The codes employed to design these concrete mixes are kept similar to the original 122 ones ( $\mathrm{C} 1$ to $\mathrm{C} 31$ ), as presented in [Dérobert and Villain, 2017b], in order to facilitate subsequent studies by 123 readers. The effective water-cement ratio $(\mathrm{W} / \mathrm{C})$ ranges from 0.35 to 0.55 , resulting in a porosity varying 124 from $6.7 \%$ to $17.1 \%$. Standard Portland cement CEM I 42.5 R (Heidelberg Group) has been used, and the 125 aggregates originating in the Nantes (FR) region are either calcareous (Boulonnais) or siliceous (Palvadeau).

Table 1: Concrete mix design and average porosity (Epsilon project)

\begin{tabular}{|c|c|c|c|c|c|c|c|}
\hline Code & Aggregate type & $\begin{array}{c}\text { Gravel } \\
4 / 20 \\
\left(\mathrm{~kg} / \mathrm{m}^{3}\right)\end{array}$ & $\begin{array}{c}\text { Sand } \\
0 / 4 \\
\left(\mathrm{~kg} / \mathrm{m}^{3}\right)\end{array}$ & $\begin{array}{r}\text { CEM I } \\
\left(\mathrm{kg} / \mathrm{m}^{3}\right)\end{array}$ & $\begin{array}{c}\text { W/C } \\
(-)\end{array}$ & $\begin{array}{l}\text { AEA* } \\
\text { Fosroc }\end{array}$ & $\begin{array}{c}\text { Poro. } \\
\text { (\%) }\end{array}$ \\
\hline $\mathrm{C} 1$ & Calcareous & 1008 & 1008 & 350 & 0.35 & - & 13.7 \\
\hline $\mathrm{C} 3$ & Siliceous & 932 & 932 & 410 & 0.35 & - & 8.9 \\
\hline $\mathrm{C} 5$ & Siliceous & 985 & 985 & 350 & 0.35 & Yes & 6.7 \\
\hline $\mathrm{C} 7$ & Calcareous & 953 & 953 & 410 & 0.35 & Yes & 10.8 \\
\hline $\mathrm{C} 13$ & Siliceous & 917 & 917 & 350 & 0.5 & - & 10.8 \\
\hline
\end{tabular}




$\begin{array}{llllllll}\text { C15 } & \text { Calcareous } & 872 & 872 & 40 & 0.5 & - & 14.6 \\ \text { C17 } & \text { Calcareous } & 939 & 939 & 350 & 0.5 & \text { Yes } & 15.5 \\ \text { C19 } & \text { Siliceous } & 853 & 853 & 410 & 0.5 & \text { Yes } & 16.9 \\ \text { C25 } & \text { Calcareous } & 916 & 916 & 350 & 0.55 & - & 13.5 \\ \text { C27 } & \text { Siliceous } & 826 & 826 & 410 & 0.55 & - & 13.6 \\ \text { C29 } & \text { Siliceous } & 894 & 894 & 350 & 0.55 & \text { Yes } & 17.1 \\ \text { C31 } & \text { Calcareous } & 845 & 845 & 410 & 0.55 & \text { Yes } & 14.9\end{array}$

*Air-entraining agent (AEA)

130 Three cylindrical samples ( $\gg 75 \times 70 \mathrm{~mm}$ ) per test concrete were cored and 3 slabs $(230 \times 230 \times 70 \mathrm{~mm})$ 131 sawn. Additional non-carbonated (NC) samples enabled determining the porosity. One core was preserved

132 from carbonation (sample A) per concrete. Another core (sample B) was dried in an oven in order to reach a

133 constant mass corresponding to an equilibrium at RH $=50 \%$. Similarly, for each mix, 3 slabs $(\sim 22 \times 22 \times 6$

$134 \mathrm{~cm}$ ) were sawn for capacitive measurements.

135 All the B samples and slabs were then placed in a chamber at approx. $\mathrm{T}=20^{\circ} \mathrm{C}, \mathrm{RH}=50 \%$ and $\left[\mathrm{CO}_{2}\right]=50 \%$

136 for 3 months, with samples being weighed once a month. The mass increased substantially during the first 2

137 months, while the last month tapered off or stabilized. The relative mass increase measured and calculated

138 between times t 0 and $t 0+3$ months, as well as the predicted mean values and variation ranges using

139 Papadakis' model, are summarized in Table 2: the values remain similar, with the measured values being

140 slightly lower. For each concrete, porosity was measured by means of water saturation on one core per state.

Table 2: Comparison of relative mass increases due to carbonation: estimated values by Papadakis' model with measured and calculated values after 3 months of accelerated carbonation (color legend: darkmedium-light gray and white as high, middle, low and very low levels of uncertainty, respectively). Code Relative mass increase (\%)

\begin{tabular}{cccc} 
& Estimated & Slabs & Cylinders \\
\hline C1 & $4 . \pm 0.1$ & 4.5 & 3.7 \\
C3 & $4.8 \pm 0.1$ & 3.2 & 2.9 \\
C5 & $4.2 \pm 0.1$ & 2.6 & 3.1 \\
C7 & $4.6 \pm 0.3$ & 4.4 & 3.7 \\
C13 & $4.6 \pm 0.3$ & 4.9 & 4.2 \\
C15 & $5.4 \pm 0.4$ & 5.8 & 5.3 \\
C17 & $4.6 \pm 0.4$ & 4.7 & 3.2 \\
C19 & $5.6 \pm 0.3$ & 4.5 & 3.5 \\
C25 & $4.6 \pm 0.3$ & 5.3 & 4.2 \\
C27 & $5.6 \pm 0.3$ & 5.6 & 4.7 \\
C29 & $4.8 \pm 0.5$ & 3.3 & 2.4 \\
C31 & $5.4 \pm 0.6$ & 4.7 & 3.7 \\
\hline
\end{tabular}

\section{Color code}

Increase/Estimated

$(-)$

$[-0.4,-0.55]$

[-0.2, -0.4[$

$[+0.2,-0.2[$ 
146 For low-porosity concretes (C3 and C5), the measured values are less than the estimated values of relative 147 mass increases. This result can be attributed to incomplete carbonation. For very porous concretes (C19 and

148 C29), the samples should be completely carbonated; meanwhile, these carbonated samples were stored in the 149 carbonated chamber at $\mathrm{RH}=50 \%$ and thus could have been subjected to drying concomitant to carbonation.

150 Furthermore, for all concretes mixed with an air-entraining agent (C5 and C7, C17 and C19, C29 and C31),

151 porosity is high and may lead to overestimating the mass increase with Papadakis' model, which could

152 provide a second plausible explanation of the differences observed in Table 2 for porous concretes C19 and

153 C29.

154 Once the carbonation process had been performed, samples A and B were saturated under vacuum and tested 155 in the cylindrical coaxial EM cell.

\subsection{Concrete mix design from the ANR-SENSO project}

158 The mix design used for the ANR-SENSO experimental program, in which only 5 concretes were subjected 159 to carbonation, is presented in Table 3. Two additional slabs, cured just like the others, were cored in order to 160 characterize the concretes [Balayssac et al., 2012]. For each design, porosity was measured by means of 161 water saturation on four cores from the first additional slab. The mean value and standard deviation are given 162 in Table 3. The effective water-cement ratio ranges from 0.57 to 0.9 , thus inducing a porosity from $14.9 \%$ to $16318.1 \%$.

164 Similarly to the Epsilon project, Portland cement CEM I and aggregates, either calcareous or siliceous, were used. Combining both projects extends the water-cement ratio from 0.35 to 0.9 , corresponding to a range of porosity from $6.7 \%$ to $18.1 \%$.

Table 3: Concrete mix design and average porosity (ANR-SENSO project)

\begin{tabular}{cccccccc}
\hline Code & Aggregate type & $\begin{array}{c}\text { Gravel } \\
\mathbf{4 / 1 4} \\
\left(\mathbf{k g} / \mathbf{m}^{\mathbf{3}}\right)\end{array}$ & $\begin{array}{c}\text { Sand 0/4 } \\
\left(\mathbf{k g} / \mathbf{m}^{3}\right)\end{array}$ & $\begin{array}{c}\text { CEM I } \\
\left(\mathbf{k g} / \mathbf{m}^{3}\right)\end{array}$ & $\begin{array}{c}\text { Water } \\
\left(\mathbf{k g} / \mathbf{m}^{3}\right)\end{array}$ & $\begin{array}{c}\text { W/C } \\
\mathbf{( - )}\end{array}$ & $\begin{array}{c}\text { Poro. } \\
(\mathbf{\%})\end{array}$ \\
\hline G3 & Siliceous & 1069 & 774 & 370 & 211.6 & 0.57 & $15.5 \pm 0.5$ \\
G3a & Siliceous & 1069 & 774 & 370 & 211.6 & 0.57 & $16.0 \pm 0.7$ \\
G7 & Siliceous & 1047 & 839 & 320 & 216.32 & 0.68 & $15.9 \pm 0.8$ \\
G8 & Siliceous & 1016 & 938 & 240 & 217.2 & 0.9 & $18.1 \pm 1.0$ \\
G6 & Calcareous & 1138 & 758 & 370 & 214 & 0.58 & $14.9 \pm 0.4$
\end{tabular}

170 A total of 9 slabs $(50 \times 25 \times 12 \mathrm{~cm})$ were cast per test concrete. After a campaign devoted to studying water 171 content [Dérobert and Villain, 2017b], 4 slabs per concrete were dried in an oven in order to reach a constant 172 mass, corresponding to an equilibrium at $\mathrm{RH}=50 \%$, and then wrapped to homogenize water content inside 173 the slabs. They were then subjected to accelerated carbonation under controlled conditions at about $\mathrm{T}=$ 
$17420^{\circ} \mathrm{C}, \mathrm{RH}=50 \%$ and $\left[\mathrm{CO}_{2}\right]=50 \%$ until the corresponding small sample had reached the required

175 carbonation depth $\mathrm{Pc}$ at around 10,20, 40 and $60 \mathrm{~mm}$. The accelerated carbonation was verified by

176 carbonation depth measurements conducted on additional samples (Table 4). For this step, several cores

177 (from the $2^{\text {nd }}$ additional slab) were subjected to the same curing, preconditioning and accelerated carbonation

178 conditions. For each concrete, a core was split and sprayed with a phenolphthalein solution at different test

179 times in order to determine carbonation depth according to the RILEM procedure "TC56-MHM

180 Hydrocarbon materials, CPC-18 Measurement of hardened concrete carbonated depth". Once the targeted

181 carbonation depth had been reached on this reference core, two carbonated slabs of the same concrete were

182 removed from the carbonation chamber and carefully protected until the non-destructive test.

183 Parameters P0, P40 and P60, appended to the codes in Table 4, correspond to the following carbonation

184 depth target values: 0,40 , and $60 \mathrm{~mm}$, respectively.

185

186

Table 4: Carbonation depths and porosity decreases

\begin{tabular}{ccccc}
\hline Code & $\begin{array}{c}\text { Targeted } \\
\text { Pc (mm) }\end{array}$ & $\begin{array}{c}\text { Porosity } \\
(\mathbf{\%})\end{array}$ & $\begin{array}{c}\text { Poro. } \\
\text { difference } \\
(\mathbf{\%})\end{array}$ & $\begin{array}{c}\text { Measured } \\
\text { Pc (mm) }\end{array}$ \\
\hline G3-Pc0 & 0 & 16.2 & 2.8 & 1 \\
G3-Pc40 & 40 & 13.4 & & 31 \\
G3a-Pc0 & 0 & 15 & 2.6 & 1 \\
G3a-Pc40 & 40 & 12.4 & & 29 \\
G7-Pc0 & 0 & 15.8 & 1.6 & 3 \\
G7-Pc40 & 40 & 14.2 & & 42 \\
G8-Pc0 & 0 & 18.1 & 2.8 & 5 \\
G8-Pc60 & 60 & 15.3 & & 60 \\
G6-Pc0 & 0 & 17.2 & 4.5 & 2 \\
G6-Pc40 & 40 & 12.7 & & 27 \\
\hline
\end{tabular}

Note the extreme difficulty in reaching Pc $=40 \mathrm{~mm}$, as the actual value in most cases was closer to $30 \mathrm{~mm}$.

Moreover, the decrease in porosity is slightly too small for G7, perhaps because a high poresity of the non-carbonated (NC) sample that should be around 15\% (Table 3). In fact, except for G8, it proved to be very difficult, or even impossible, to reach complete carbonation corresponding to $\mathrm{Pc}=60 \mathrm{~mm}$ (on both faces) after several months in the carbonation chamber. All slabs were then saturated and tested using different NDT methods, in particular capacitive and GPR techniques (as described in the following section).

\subsection{NDT methods}

196 Within the framework of this study, two EM NDT techniques were used (i.e. capacitive technique and GPR), complemented by measurements in an EM cell. All 3 techniques and methodologies will be described below. 
200 The radar technique employed relied on a commercial GPR system, using SIR-3000 systems from

201 Geophysical Survey Systems, Inc. (GSSI®) and two separate ground-coupled 1.5-GHz antennas. GPR relies

202 on the principle that electromagnetic wave pulses are transmitted through the investigated medium. As the

203 EM signal passes through this medium, partial reflections occur at each interface, thus presenting EM

204 contrasts that can be acquired as time signals by the receiving antenna. The recent literature detailing this

205 technique includes Jol [2009], Pajewski and Benedetto [2011], Persico [2014] and Utsi [2017]. As regards

206 concrete, the signals received are mainly analyzed in terms of time delay and pulse echo amplitude [Laurens,

207 et al., 2002; Dérobert et al., 2008].

208 The GPR methodology proposed herein focuses on the direct wave in the medium recorded by the bistatic

209 antennas using four offsets (transmitter-receiver distance) ranging from 7 to $14 \mathrm{~cm}$, which in most instances

210 are compatible with rebar mesh sizes. For our purposes, a commercial bistatic antenna was adapted to

211 variable offsets while separating the shielded antennas and retaining the electronics and their connection

212 (Fig. 2). An absorbent foam was placed between the transmitter and receiver during static measurements in

213 order to measure the wave without distortion due to the direct air wave [Villain et al., 2012]. All

214 measurements were performed in air as the initial step, and subsequently on the concrete at three

215 measurement points for each offset (Fig. 3a). After peaking the maximum direct wave (DW) for every offset,

216 the velocity and relative permittivity can then be calculated (Fig. 3b). Since the antennas are coupled to the

217 surveyed medium, the central frequency decreases towards approx. $900 \mathrm{MHz}$ on saturated concretes, which

218 is why results derived from GPR will be associated with the 900-MHz frequency in the following.

219 Few observables are studied with this configuration, i.e.: velocity, the corresponding relative permittivity,

220 and attenuation from the direct wave. For this attenuation, the studied observable corresponds to the slope

221 coefficient of the logarithm of normalized amplitudes of the four offsets (herein called amplitude-slope): the

222 greater the slope, the less electromagnetically attenuating the medium.

223

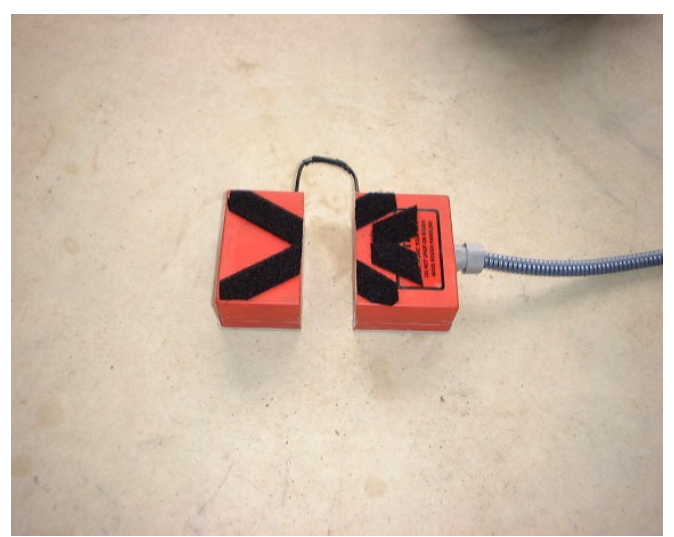

Fig. 2: Adaptation of a variable-offset bistatic configuration from one commercial 1.5-GHz antenna 

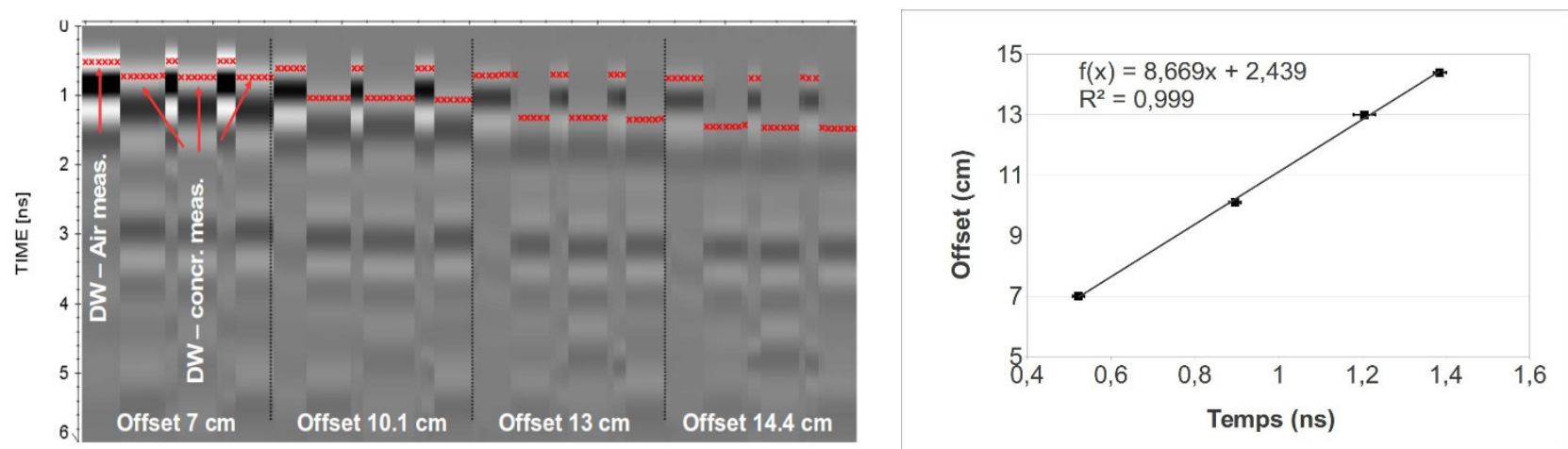

Fig. 3a) Example of GPR CMP performed on concrete G3 before carbonation - Presentation of the direct waves (DW) from air and concrete measurements at three positions; b) Calculation of GPR velocity from the peaking data

\subsubsection{Capacitive technique}

The principle of the capacitive technique relies on the resonance frequency measurement of an oscillating circuit (approx. $33 \mathrm{MHz}$ ) between electrodes lying on the upper face of the test plane medium [Dérobert et al., 2008; Fares et al., 2016]. This set-up forms a coplanar capacitor. The changes in capacitance, which induce a shift in resonance frequency, are indicative of concrete constituents and conditions. A preliminary calibration on known materials outputs the relative permittivity of the tested material, which is viewed as a homogeneous medium. A panel of three sets of electrodes (investigation depth equal to 2-3 $\mathrm{mm}$ for electrodes labeled SE, 1-2 cm for ME, 7-8 cm for GE) yields information on a possible gradient depth function (Fig. 4).

For the present study, only those results obtained with the GE electrodes are shown. The thickness coupled with a set of electrodes, most closely resembling that from the GPR direct wave, actually corresponds to GE electrodes. Moreover, since a thin superficial layer was carbonated on ANR-SENSO slabs during NDT measurements ( 1 to $2 \mathrm{~mm}$ ), the GE electrodes were least sensitive to this layer, leading to the assumption that its effect was negligible.

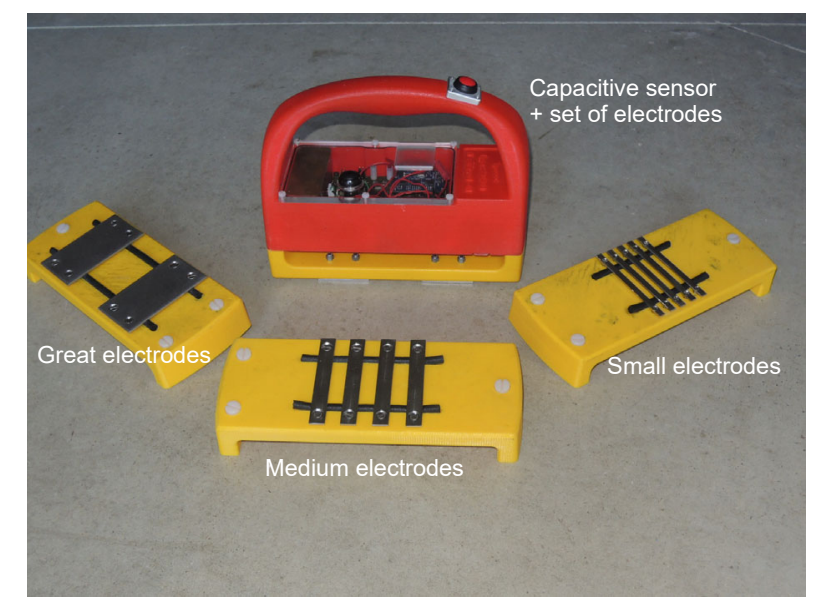

Fig. 4: Capacitive measurement system with 3 different sets of electrodes (SE, ME, GE)

\subsubsection{Coaxial cylindrical EM cell}

An EM cell measurement was designed to characterize bound civil engineering materials, i.e. cement as well as bituminous concrete, through complex relative permittivity at radar frequencies typically extending from $50 \mathrm{MHz}$ to about 1-1.4 GHz, with the upper limit depending on material permittivity. An iterative inversion 
249 procedure enabled retrieving the complex relative permittivity of the material from the reflection coefficient 250 measurements [Adous et al., 2006], thus deriving the dispersion curve (relative permittivity vs. frequency). 251 The benefit of such an EM cell is twofold: to characterize civil engineering mixes over a large radar

252 frequency band; and to correlate the measurements conducted by the two NDT techniques, namely capacitive 253 and GPR, operating at both ends of this frequency band. In order to extrapolate the relative permittivity at $25433 \mathrm{MHz}$ (or $1 \mathrm{GHz}$ ) from EM cell measurements and compare all results with those of the NDT technique, a 255 Jonscher's model was then introduced to fit the dispersion curve [Ihamouten et al., 2011]. 


\section{Results and analysis}

2584.1 Effect of carbonation on the complex relative permittivity

259 The NC cores (A) and carbonated cores (B) from Table 1 were tested in the EM coaxial cell under saturated 260 conditions. The dispersion curve of the complex relative permittivity was obtained with an averaged higher 261 frequency, depending on the value of the real part of permittivity (dielectric constant), limited at between 262 approx. $750 \mathrm{MHz}$ and $1 \mathrm{GHz}$. An example for concretes mixed with calcareous aggregates (C15) is given in 263 Figure 5 and another with siliceous aggregates (C27) in Figure 6. As is the case for all concretes (except C3 264 and C29, which were not sufficiently carbonated, see Table 2), the complex permittivity decreases 265 significantly with carbonation, especially at low frequency for the real part. Moreover, the carbonated 266 saturated samples are less dispersive than the other samples.

267

a)

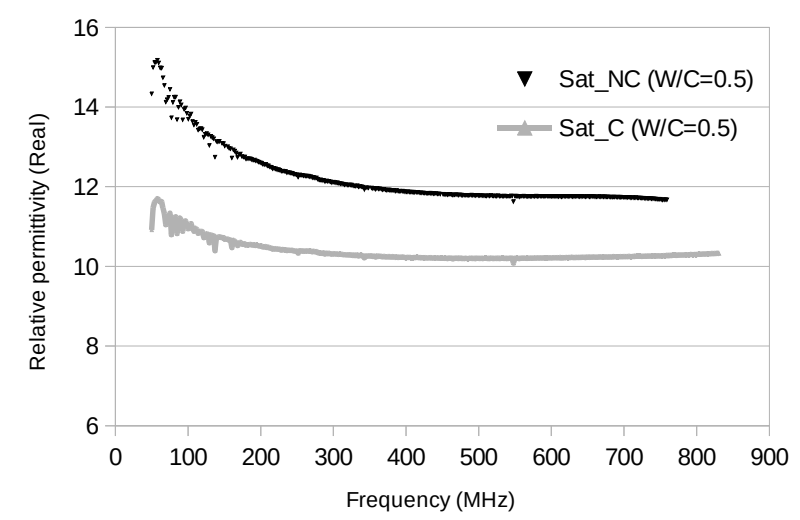

b)

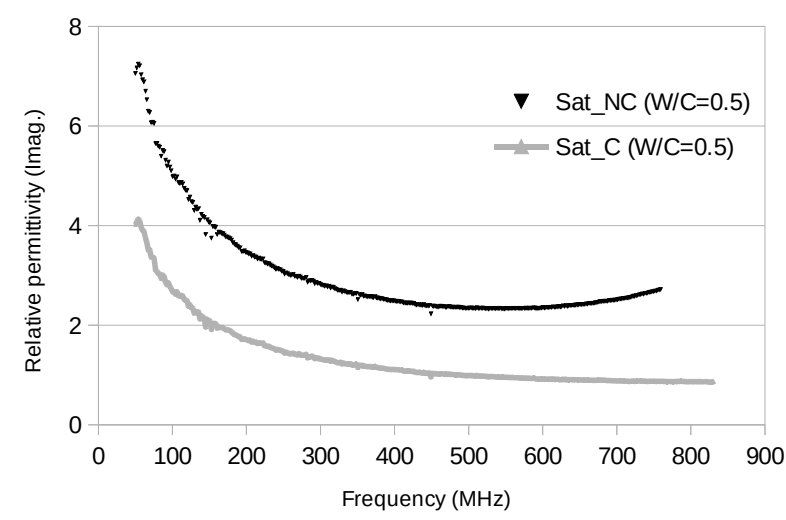

a)

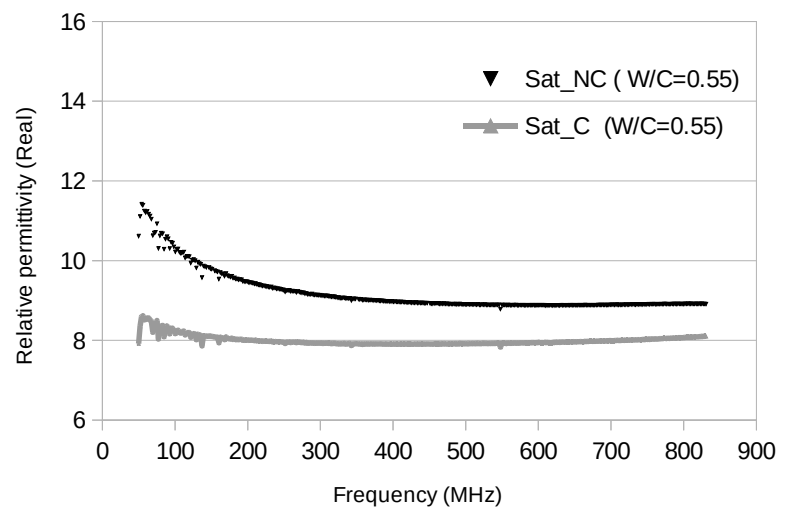

b)

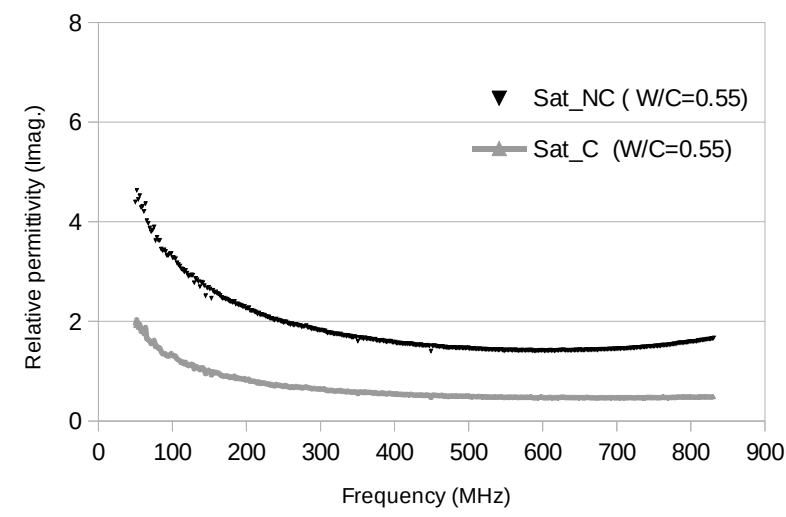

Fig. 5: Complex permittivity of carbonated (C) and non-carbonated (NC) saturated concrete C15 (calcareous aggregates, cement $410 \mathrm{~kg} \cdot \mathrm{m}^{-3}$ and $\mathrm{W} / \mathrm{C}=0.5$ ): a) Real part; b) Imaginary part

Fig. 6: Complex permittivity of carbonated (C) and non-carbonated (NC) saturated concrete $\mathrm{C} 27$ (siliceous aggregates, cement $410 \mathrm{~kg} \cdot \mathrm{m}^{-3}$ and $\left.\mathrm{W} / \mathrm{C}=0.55\right)$ : a) Real part; b) Imaginary part

This decrease in permittivity may be due to the porosity reduction, estimated at approx. $4 \%$ (absolute value) 
the decrease in small mobile hydroxyl ions $\left(\mathrm{OH}^{-}\right)$. Another explanation could be the filling of smaller pores

278 (Fig. 1) combined with less tortuosity, which induces a reduction in the capacitive effects of the various ions 279 contained in these pores.

280 Note that these explanation are similar to those given for the increase in resistivity induced by carbonation 281 [Alonso et al., 1988; Glass et al., 1991].

282 The second observation focuses on the dispersive effects of permittivity at low frequency, which increase due 283 to the Maxwell-Wagner effect as the W/C ratio decreases, as explained by the lower pore diameters.

284 Let's also note the carbonation of high performance concretes, with such a low W/C ratio and hence low 285 porosity, is a very long and difficult process. Despite 3 months of exposure to a high carbon dioxide content, 286 the carbonation process might still be incomplete for less porous concretes. A model based on a Portland 287 cement quantity and W/C established by Papadakis et al. [1991a-b] found that the mass increase of a 288 complete carbonation process is bound to be slightly overestimated, with the less porous concretes not being 289 fully carbonated (dark and medium gray in Table 4).

290 Concerning concretes $\mathrm{C} 3$ and C29, there must be an experimental problem, as $\mathrm{C} 29$ is a highly porous291 concrete ( $\varphi$ - $1 / 417.1 \%)$ that should carbonate easily. This lack of carbonation may be due to the air-entraining 292 agent that induces a closed porosity, but this is merely a hypothesis although noted on the other mixes293 eentaining AEA. even though permittivity results show similar trends to those of C15 and C27, with slight 294 decreases in permittivity, they should not be taken into account and are thus not presented herein.

295 Lastly, the difference in permittivity observed between NC samples of concretes mixed with calcareous and 296 siliceous aggregates is solely due to the permittivity of the coarse aggregates.

\subsection{Effect of carbonation on EM NDT techniques}

299 The primary results from the ANR-SENSO project are listed in Table 5, with all mixes being considered 300 homogeneous. The mean value and standard deviation correspond to several measurements performed at 3 points on the surface of the same slab. First, it can be underscored that the real part of the relative permittivity (or dielectric constant) is lower for carbonated slabs than for NC slabs, at low frequency for capacitive measurements as well as at higher frequencies for GPR measurements (though to a much lesser extent). This decrease is attributed to a drop in porosity, thus leading to less volumetric water content in the mixes. A special comment is warranted for concrete G6, since its aggregates are of a different type. Calcareous coarse aggregates do involve mostly higher permittivity values, as G6 behaves like the other mixes under a carbonation process from an EM standpoint. For GPR, the measurement conducted on the G6_NC slab seems to be compromised and has thus been excluded. 

due to carbonation (ANR-SENSO project)

\begin{tabular}{ccccc}
\hline Code & Porosity (\%) & $\begin{array}{c}\text { Capa_GE } \\
\text { permittivity } \\
(-)\end{array}$ & $\begin{array}{c}\text { GPR } \\
\text { permittivity } \\
(-)\end{array}$ & $\begin{array}{c}\text { GPR amplitude- } \\
\text { slope }(-)\end{array}$ \\
\hline G3-P0 & 16.2 & $15.4 \pm 0.6$ & $10.3 \pm 1.3$ & $0.34 \pm 0.04$ \\
G3-P40 & 13.4 & $12.4 \pm 0.1$ & $9.7 \pm 0.3$ & $0.50 \pm 0.03$ \\
G3a-P0 & 15 & $14.5 \pm 0.1$ & $12.0 \pm 0.7$ & $0.47 \pm 0.03$ \\
G3a-P40 & 12.4 & $11.6 \pm 0.2$ & $9.7 \pm 0.1$ & $0.52 \pm 0.01$ \\
G7-P0 & 15.8 & $15.5 \pm 0.1$ & $11.7 \pm 0.7$ & $0.44 \pm 0.01$ \\
G7-P40 & 14.2 & $12.9 \pm 0.1$ & $10.6 \pm 0.6$ & $0.47 \pm 0.02$ \\
G8-P0 & 18.1 & $15.2 \pm 0.1$ & $12.4 \pm 0.5$ & $0.38 \pm 0.02$ \\
G8-P60 & 15.3 & $13.0 \pm 0.2$ & $11.8 \pm 0.6$ & $0.49 \pm 0.02$ \\
G6-P0 & 17.2 & $16.5 \pm 0.1$ & $11.5 \pm 0.5$ & $0.39 \pm 0.01$ \\
G6-P40 & 12.7 & $14.0 \pm 0.1$ & $11.7 \pm 0.4$ & $0.42 \pm 0.01$ \\
\hline
\end{tabular}

314 The increase in the radar amplitude-slope of the direct wave (Fig. 7b), in the carbonated material, deserves to be highlighted; it is correlated with the decrease in wave attenuation, hence with the decrease in the imaginary part of the relative permittivity, due to less volumetric water quantity in the saturated concretes. In assuming two outliers, the GPR amplitude-slope and relative permittivity show linear sensitivities to porosity (Fig. 7b). However, the lower level of uncertainty of the amplitude-slope leads to considering this observable as more efficient for carbonation detection.

a)

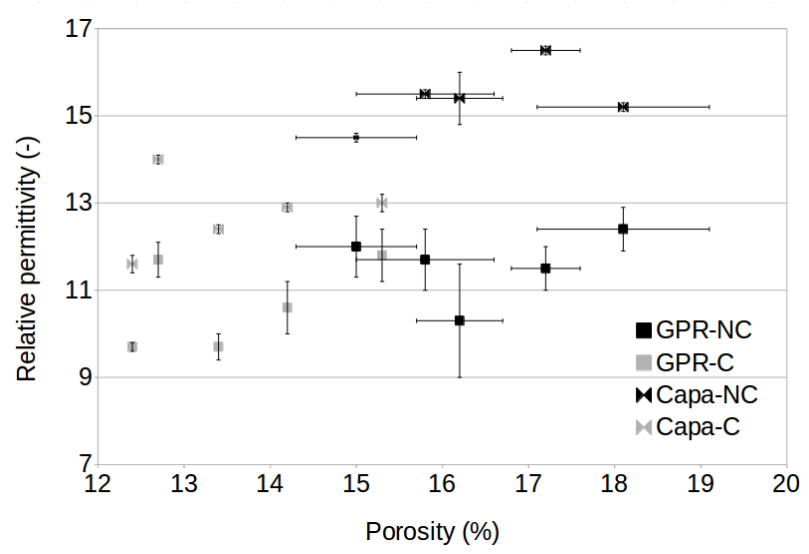

b)

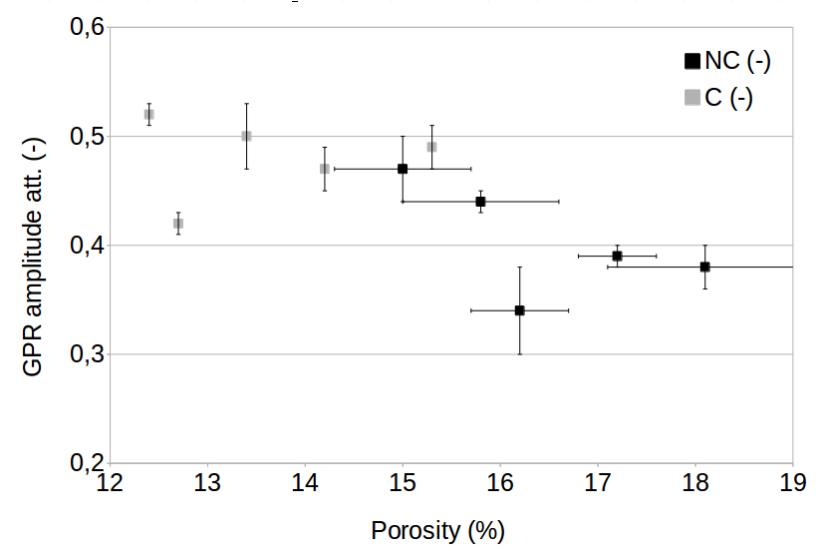

Fig. 7: a) GPR relative permittivity and (b) GPR amplitude-slope vs. porosity for carbonated and non-carbonated concrete mixes (ANR-SENSO project)

NDT techniques could be performed during the carbonation process as the carbonation depth could be measured. Figure 8 presents the evolution in relative permittivity vs. carbonation depth measured by both capacitive and GPR techniques on all mixes. We can detect a decreasing slope over the first 20 millimeters until reaching a plateau, which is clearly visible in Figure 8a for capacitive measurements. This finding can be interpreted as an increase in the share of carbonation thickness within the volume coupled to the GE 
electrodes (assimilated to a depth penetration). Once the carbonation thickness has exceeded the coupled volume limit, the capacitive technique designates the concrete as homogeneous and shows stable values.

330 These results indicate that, in practice, GE electrodes remain sensitive until roughly $20 \mathrm{~mm}$ for carbonation detection, i.e. much less than reported in previous studies for water content detection [Fares et al., 2016].

a)

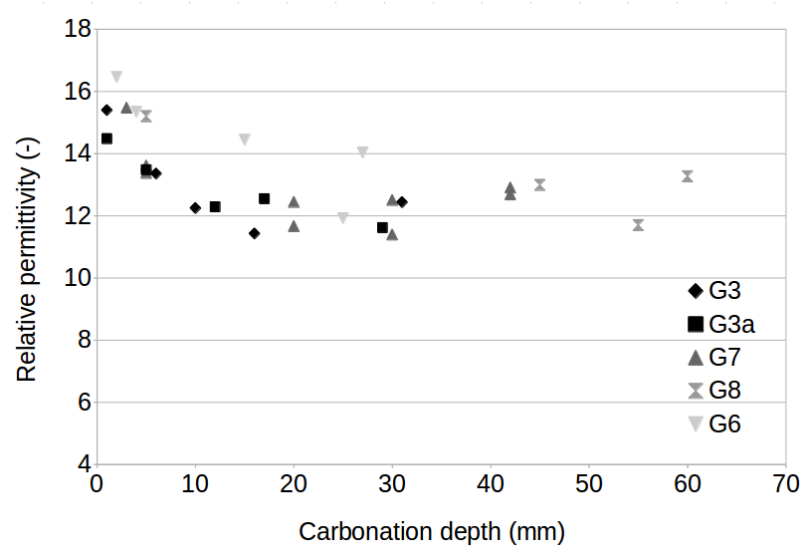

b)

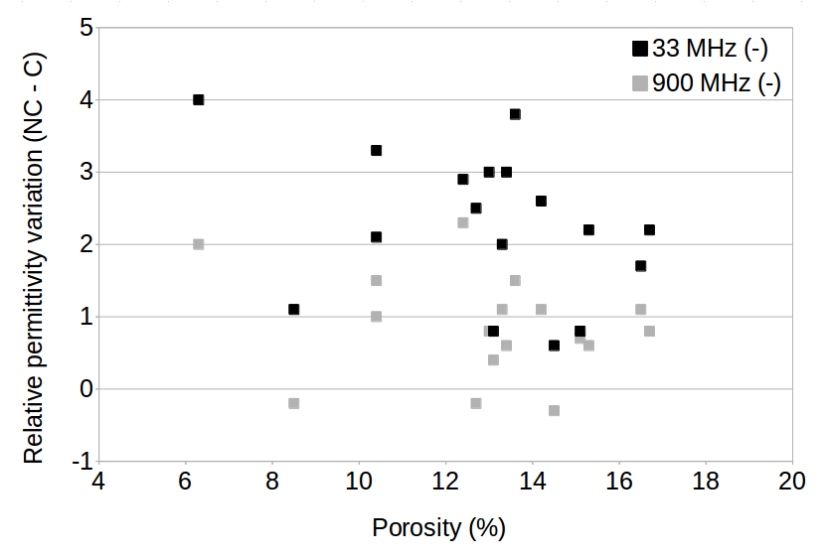

Fig. 8: Relative permittivity vs. carbonation depth during the carbonation process obtained by: a) capacitive technique, b) GPR

For the GPR results, the measurements display a slight decrease in evolution vs. carbonation depth (Fig. 7b), which is more visible over the first 20 millimeters. The underlying interpretation remains quite complex as several phenomena are interacting. The direct wave, whose maximum amplitude has peaked, corresponds to the sum of the direct wave in the medium, the faint direct air wave (as the antennas are shielded) and a possible guided wave propagating in the carbonated layer.

Concerning the Epsilon project, the deduced relative permittivity values, as obtained from EM cell measurements using Jonscher's model fitting at 33 and $900 \mathrm{MHz}$, are presented in Table 6. These results are rather similar to those from the ANR-SENSO project (Table 5), by showing decreases in relative permittivity with carbonation that are more pronounced at low frequencies than at the GPR frequency.

Moreover, capacitive measurements could be performed, following the project, on carbonated slabs (B samples) after saturation. The limitation with this method lies in the fact that the capacitive system was not available during the Epsilon project, in which concrete slabs (A samples) were not subjected to natural carbonation. Once available, the natural carbonation had progressed and was therefore no longer negligible in the capacitive measurements, which then could no longer be carried out on non-carbonated mixes.

The capacitive results, as featured in Table 6, show good agreement with the results obtained from the EM cell at the same frequency. 
Table 6: Variation in relative permittivity values at 33 and $900 \mathrm{MHz}$ due to carbonation (Epsilon project)

\begin{tabular}{|c|c|c|c|c|c|}
\hline Code & $\underset{(-)}{\text { Capa_GE }}$ & $\begin{array}{c}\text { Jonscher's fitting } \\
33 \text { MHz (-) }\end{array}$ & $\begin{array}{l}\text { Decrease } \\
33 \mathrm{MHz}\end{array}$ & $\begin{array}{c}\text { Jonscher's fitting } \\
\text { at } 900 \mathrm{MHz}(-)\end{array}$ & $\begin{array}{l}\text { Decrease } \\
900 \mathrm{MHz}\end{array}$ \\
\hline $\mathrm{C} 1 \_\mathrm{NC}$ & & 14.7 & \multirow{2}{*}{2.0} & 11.9 & \multirow{2}{*}{1.1} \\
\hline $\mathrm{C} 1 \_\mathrm{C}$ & 12.64 & 12.7 & & 10.8 & \\
\hline $\mathrm{C} 3 \_\mathrm{NC}$ & & 9.2 & \multirow{2}{*}{1.1} & 7.1 & \multirow{2}{*}{-0.2} \\
\hline C3_C & 7.82 & 8.1 & & 7.3 & \\
\hline B5A_NC & & 11.6 & \multirow{2}{*}{4.0} & 8.8 & \multirow{2}{*}{2.0} \\
\hline B5B_C & 5.78 & 7.6 & & 6.8 & \\
\hline B7A_NC & & 12.5 & \multirow{2}{*}{2.0} & 10.4 & \multirow{2}{*}{1.0} \\
\hline B7B_C & 10.63 & 10.4 & & 9.4 & \\
\hline B13A_NC & & 11.0 & \multirow{2}{*}{3.3} & 8.8 & \multirow{2}{*}{1.5} \\
\hline B13B_C & 8.65 & 7.7 & & 7.3 & \\
\hline B15A_NC & & 15.7 & \multirow{2}{*}{3.8} & 11.7 & \multirow{2}{*}{1.4} \\
\hline B15B_C & 12.73 & 11.9 & & 10.2 & \\
\hline B17A_NC & & 13.1 & \multirow{2}{*}{0.8} & 11.8 & \multirow{2}{*}{0.8} \\
\hline B17B_C & 14.02 & 12.3 & & 11.1 & \\
\hline B19A_NC & & 12.8 & \multirow{2}{*}{1.7} & 10.9 & \multirow{2}{*}{1.0} \\
\hline B19B_C & 11.32 & 11.1 & & 9.8 & \\
\hline B25A_NC & & 14.2 & \multirow{2}{*}{0.8} & 11.6 & \multirow{2}{*}{0.4} \\
\hline B25B_C & 12.60 & 13.4 & & 11.2 & \\
\hline B27A_NC & & 11.7 & \multirow{2}{*}{3.1} & 8.8 & \multirow{2}{*}{0.8} \\
\hline B27B_C & 10.06 & 8.7 & & 8.0 & \\
\hline B29A_NC & & 14.4 & \multirow{2}{*}{2.2} & 12.6 & \multirow{2}{*}{0.8} \\
\hline B29B_C & 14.02 & 12.2 & & 11.8 & \\
\hline B31A_NC & & 13.3 & \multirow{2}{*}{0.5} & 11.5 & \multirow{2}{*}{-0.2} \\
\hline B31B_C & 15.34 & 12.7 & & 11.8 & \\
\hline
\end{tabular}

354

\subsection{Comparison with the EM results}

356 Figure 9a compiles all EM results, in focusing on the relative permittivity of saturated carbonated mixes vs.

357 porosity. The measurements performed at $33 \mathrm{MHz}$ are depicted in black dots and those at $900 \mathrm{MHz}$ in gray.

358 Let's note an apparent linear increase with porosity, mainly due to an increase in the volumetric water content

359 filling the pores. The variation in relative permittivity between non-carbonated and carbonated mixes is

360 highlighted in Figure 9b. These variation values are roughly in the range of 2 at $33 \mathrm{MHz}$ and 1 towards 900

$361 \mathrm{MHz}$. 
a)

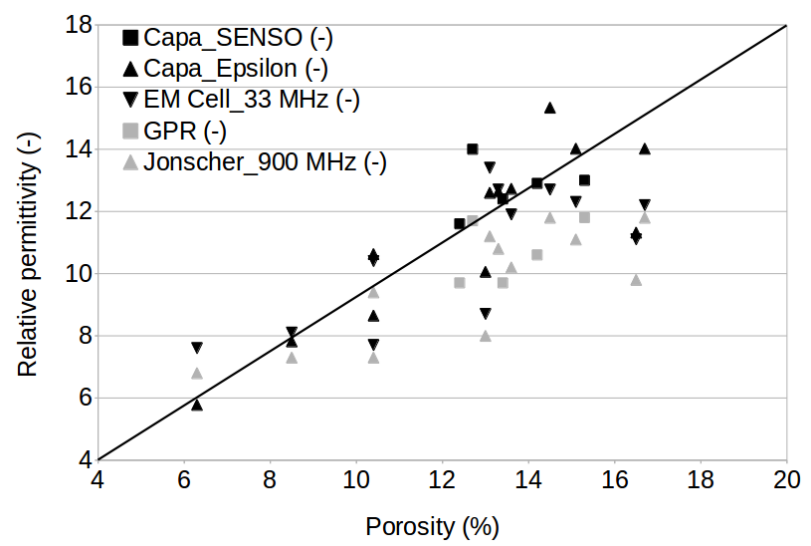

b)

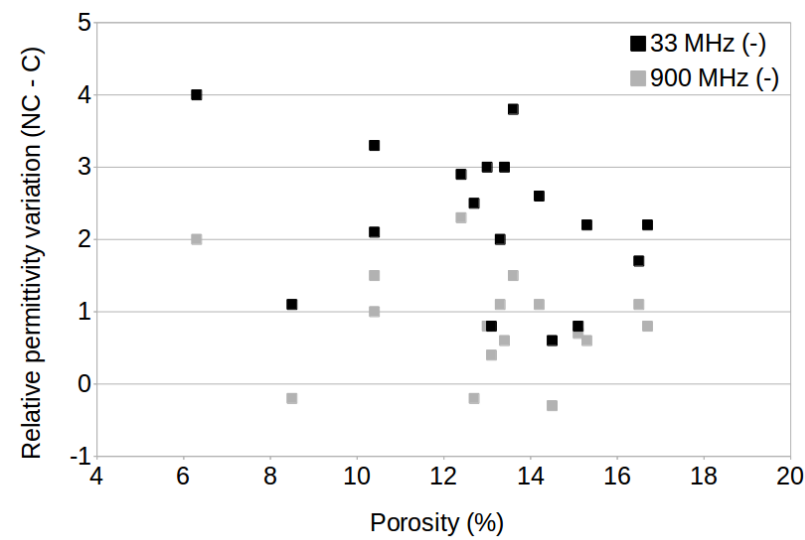

a)

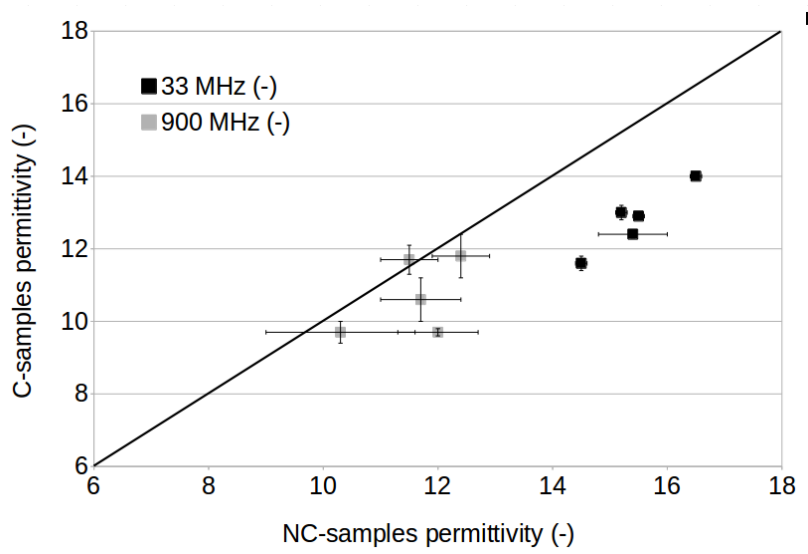

b)

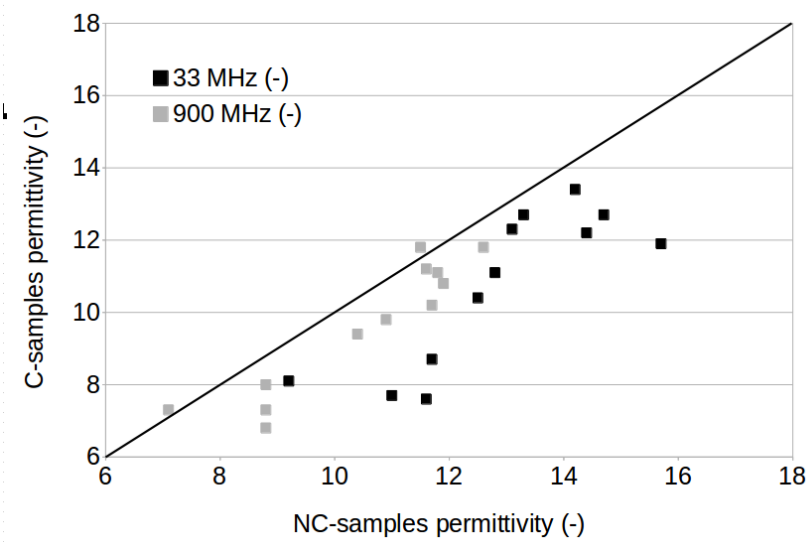

Fig. 10: Sensitivity to carbonation on capacitive techniques at $33 \mathrm{MHz}$ and on GPR at $900 \mathrm{MHz}$ using saturated concretes: a) ANR-SENSO project; b) Epsilon project

The decrease in the real part of permittivity, as determined by the GE capacitive technique, ranges from 2.2 to 3.0 (Table 5 and Fig. 5a) or from 0.8 to 4.0 (Table 6 and Fig. 5b). On the other hand, the decrease determined by GPR ranges between 0.6 and 2.2 or between 0.4 and 2.0 .

These findings confirm that the results of both projects are in good agreement and moreover that the capacitive technique at $33 \mathrm{MHz}$ is more sensitive than a GPR equipped with $1,500-\mathrm{MHz}$ antennas to 
385 The effect of carbonation on EM wave propagation and dispersion has been presented on $(12+5)$ different saturated concretes, along with the capability of two electromagnetic non-destructive techniques, namely capacitive and GPR, to detect this pathology. Carbonation leads to a decrease in both the real and imaginary parts of permittivity. Wave attenuation is smaller and EM wave dispersion is reduced. This outcome can be attributed both to the porosity reduction that lowers the overall water content and to ionic changes in the pore solution. The pore distribution with fewer nano-pores and more micro-pores, which modifies tortuosity, could also exert an impact, mainly at low frequencies. The reason for choosing saturated mixes was twofold: maximize the variation in permittivity of non-carbonated and carbonated mixes, and remove any bias due to water content uncertainty in the mixes.

The results obtained from two national research projects are in agreement, indicating that carbonation induces a decrease in the range of 2 at $33 \mathrm{MHz}$ and 1 towards $900 \mathrm{MHz}$ for the permittivity of concretes. Moreover, saturated carbonated mixes display a general linear trend of permittivity vs. porosity due to the volumetric water content filling the pores. Capacitive and GPR techniques could constitute useful tools for monitoring carbonation in concrete. Nevertheless, great care must be taken regarding the degree of saturation in the concrete samples since this parameter also heavily influences the EM results. For on-site ND structural evaluations, all durability indicators (porosity and degree of saturation) and degradation monitoring parameters (carbonation depth) must be assessed. Since all these indicators are capable of influencing EM NDT techniques, combining several complementary ND techniques might be required to perform independent evaluations.

\section{References}

412 Adous, M., Queffelec, P. and Laguerre, L., 2006, Coaxial/cylindrical transition line for broadband 413 permittivity measurement of civil engineering materials: Measurement Science and Technology, 177, 22414142246.

415 AFPC-AFREM, 1997, Méthodes recommandées pour la mesure des grandeurs associées à la durabilité,: in 416 Journées techniques AFPC-AFREM sur la durabilité des bétons, Toulouse, France.

417 Alonso, C., Andrade, C. and González, J.A., 1988, Relation between resistivity and corrosion rate of 418 reinforcements in carbonated mortar made with several cement types: Cement and Concr ete Research, 18, 419 687-698.

420 Balayssac, J.P., Laurens, S., Arliguie, G., Breysse, D., Garnier, V., Dérobert, X. and Piwakowski, B., 2012, 421 Description of the general outlines of the French project SENSO - Quality assessment and limits of different 
NDT methods: Construction and Building Materials, 35, 131-138.

423 Ballantyne, A.P, Alden, C.B., Miller, J.B., Tans, P.P. and White, J.W.C., 2012, Increase in observed net 424 carbon dioxide uptake by land and oceans during the past 50 years: Nature, 488, 70-72.

425 Benedetto A. and Pajewski L., 2015, Civil Engineering Applications of Ground Penetrating Radar, Eds: 426 Benedetto A. and Pajewski, Springer, 371 pp.

427 De Larrard, T., Bastidas-Arteaga, E., Duprat, F. and Schoefs, F., 2014, Effects of climate variations and 428 global warming on the durability of RC structures subjected to carbonation: Civil Engineering and 429 Environmental Systems, 31, 153-164.

430 Dérobert, X., Iaquinta, J., Klysz, G. and Balayssac, J.P., 2008, Use of capacitive and GPR techniques for 431 non-destructive evaluation of cover concrete: Non Destructive Testing \& Evaluation International, 41, 44-52. 432 Dérobert, X. and Villain, G., 2017a, Development of a multi-linear quadratic experimental design for the EM 433 characterization of concretes in the radar frequency-band: Construction and Building Materials, 136, 237434245.

435 Dérobert, X. and Villain, G., 2017b, EM characterization of concretes, focused on water and chloride 436 contents and carbonation, using multi-linear experimental designs in the radar frequency-band: Non 437 Destructive Testing \& Evaluation International, 92, 187-198.

438 Dunster, A.M., 1989, An investigation of the carbonation of cement paste using trimethylsilylation:

439 Advances in Cement Research, 2, 99-106.

440 Fares, M., Fargier, Y., Villain, G., Dérobert, X. and Palma-Lopes, S., 2016, Determining the permittivity 441 profile inside reinforced concrete using capacitive probes: Non Destructive Testing \& Evaluation 442 International, 79, 150-161.

443 Glass, G.K., Page, C.L. and Short, N.R., 1991, Factors affecting the corrosion rate of steel in carbonated 444 mortars: Corrosion Science, 32, 1283-1294.

445 Hernández-Paniagua, I.Y, Lowry, D., Clemitshaw, K.C, Fisher, R.E, France, J.L, Lanoisellé, M., Ramonet, 446 M. and Nisbet, E. G., 2015, Diurnal, seasonal, and annual trends in atmospheric CO2 at southwest London 447 during 2000-2012: Wind sector analysis and comparison with Mace Head, Ireland, Atmospheric 448 Environment, 105, 138-147.

449 Hong, S., Wiggenhauser, H., Helmerich, R., Dong, B., Dong, P., Xing, F., 2017, Long-term monitoring of 450 reinforcement corrosion in concrete using ground penetrating radar: Corrosion Science, 114, 123-132.

451 Hugenschmidt, J. and Loser, R., 2008, Detection of chlorides and moisture in concrete structures with GPR:

452 Materials and Structures, 41, 785-792.

453 Ihamouten, A., Chahine, K., Baltazart, V., Villain, G. and Dérobert, X., 2011, On the variants of frequency 454 power law for the electromagnetic characterization of hydraulic concrete: IEEE Transaction on 455 Instrumentation and Measurement, 60, 3658-3668.

456 Jol H.M., 2009, Ground Penetrating Radar: Theory and Applications, ed.: Jol, Elsevier, 524 pp.

457 Kalogeropoulos, A., van der Kruk, J., Hugenschmidt, J., Bikowski, J. and Brühwiler, E., 2013, Full458 waveform GPR inversion to assess chloride gradients in concrete: Non Destructive Testing \& Evaluation 459 International, 57, 74-84. 
Laurens, S., Balayssac, J.P., Rhazi, J. and Arliguie, G., 2002, Influence of concrete relative humidity on the amplitude of Ground-Penetrating radar (GPR) signal: Material and Structures, 35, 198-203.

Papadakis, V. G, Vayenas, C. G. and Fardis, M N., 1991a, Fundamental modeling and experimental investigation of concrete carbonation: ACI Materials Journal, 88, 363-373.

Papadakis, V. G, Vayenas, C. G. and Fardis, M N.,1991b, Experimental investigation and mathematical modelling of the concrete carbonation problem: Chemical Engineering Science, 46, 1333-1338.

Parrott, L.J., 1987, A Review of Carbonation of Concrete: Cement and Concrete Association, 1987, 42 pp.

Peer, S., Case, J.T., Gallaher, E., Kurtis, K.E. and Zoughi, R., 2003, Microwave reflection and dielectric properties of mortar subjected to compression force and cyclically exposed to water and sodium chloride solution: IEEE Transaction on Instrumentation and Measurement, 52, 111-118.

Persico R., 2014, Introduction to Ground Penetrating Radar - Inverse scattering and data processing, Ed: Persico, IEEE Press, 368 pp.

Ramonet, M., Delmotte, M. and Dacher, P., 2016, Un seuil record de CO2 franchi dans l'hémisphère Sud: ICOS-France, LSCE, CNRS, National Research Center, 2p. http://

www2.cnrs.fr/sites/communique/fichier/cp_amsterdam_vf_web.pdf

Robert, A., 1998, Dielectric permittivity of concrete between $50 \mathrm{Mhz}$ and $1 \mathrm{Ghz}$ and GPR measurements for building materials evaluation: Journal of Applied Geophysics, 40, 89-94

Soustos, M.N., Bungey, J.H., Millard, S.G., Shaw, M.R. and Patterson, A., 2001, Dielectric properties of concrete and their influence on radar testing: Non Destructive Testing \& Evaluation International, 34, 41925.

Tuutti, K., 1982, Corrosion of steel in Concrete: Research Report 4.82. Swedish Cement and Concrete Research Institute, Stockholm.

Utsi E., 2017, Ground penetrating radar - Theory and practice, BH Elsevier, 205 pp.

Villain, G., Ihamouten, A., du Plooy, R., Palma Lopes, S. and Dérobert, X., 2015, Use of electromagnetic nondestructive techniques for monitoring water and chloride ingress into concrete: Near Surface Geophysics, 13, 299-309.

Villain, G. and Platret, G., 2006, Comparison of two experimental methods to determine carbonation profiles in concrete: ACI Materials Journal, 103, 265-271.

Villain, G., Sbartaï, Z.M., Dérobert, X., Garnier, V. and Balayssac, J.P., 2012, Durability diagnosis of a concrete structure in a tidal zone by combining NDT methods: laboratory tests and case study.: Construction and Building Materials, 37, 893-903.

Villain, G. and Thiéry, M., 2005, Impact of carbonation on microstructure and transport properties of concrete: in Proceedings of 10th Int. Conf. on Durability of Building Materials and Components, 8 pp. Villain; G., Thiéry, M. and Platret, G., 2007, Measurement methods of carbonation profiles in concrete: thermogravimetry, chemical analysis and gammadensimetry: Cement and Concr ete Research, 7, 1182-92. 